\title{
Heterochrony: the Evolution of Development
}

\author{
Kenneth J. McNamara
}

Published online: 5 June 2012

(C) Springer Science+Business Media, LLC 2012

\begin{abstract}
Heterochrony can be defined as change to the timing or rate of development relative to the ancestor. Because organisms generally change in shape as well as increase in size during their development, any variation to the duration of growth or to the rate of growth of different parts of the organism can cause morphological changes in the descendant form. Heterochrony takes the form of both increased and decreased degrees of development, known as "peramorphosis" and "paedomorphosis," respectively. These are the morphological consequences of the operation of processes that change the duration of the period of an individual's growth, either starting or stopping it earlier or later than in the ancestor, or by extending or contracting the period of growth. Heterochrony operates both intra- and interspecifically and is the source of much intraspecific variation. It is often also the cause of sexual dimorphism. Selection of a sequence of species with a specific heterochronic trait can produce evolutionary trends in the form of pera- or paedomorphoclines. Many different life history traits arise from the operation of heterochronic processes, and these may sometimes be the targets of selection rather than morphological features themselves. It has been suggested that some significant steps in evolution, such as the evolution of vertebrates, were engendered by heterochrony. Human evolution was fuelled by heterochrony, with some traits, such as a large brain, being peramorphic, whereas others, such as reduced jaw size, are paedomorphic.
\end{abstract}

K. J. McNamara ( $\square)$

Department of Earth Sciences, University of Cambridge,

Downing Street,

Cambridge CB2 3EQ, UK

e-mail:kjm47@cam.ac.uk
Keywords Evolution · Heterochrony · Paedomorphosis · Peramorphosis $\cdot$ Sexual dimorphism $\cdot$ Evolutionary trends

\section{Introduction}

Lurking deep in Darwin's monumental tome On the Origin of Species, first published in 1859 (Darwin 1859), is a short, much neglected, section. Lying between pages 439 and 450 in the first edition and between pages 386 and 396 in my copy of the sixth edition published in 1878 is the kernel of some ideas that were intermittently to surface in the field of evolutionary theory for the following 150 years. These insights now form a major part of modern evolutionary theory. The section in question was entitled "Embryology" by Darwin in the first edition, but "Development and Embryology" in the sixth, and highlights the importance to evolution of changes to the pattern of an organism's ontogenetic development.

Darwin's (1878, p. 386) view of development and embryology was that, "This is one of the most important subjects in the whole round of natural history." But his ideas on the significance of these intrinsic aspects of evolutionary theory are scattered through much of the book and form the basis for many of Darwin's ideas on what generates the variation that is the raw material upon which natural selection operates. Darwin was undoubtedly influenced by ideas that had been around since the early nineteenth century and promulgated by embryologists like von Baer in Germany and Serres in France (see Gould 1977). Darwin (1878, p. 396) encapsulated these ideas by observing that, "Embryology rises greatly in interest, when we look at the embryo as a picture, more or less obscure, of the progenitor, either in its adult or larval state, of all members of the same great class." 
Evolution was perceived as having proceeded by an increase in complexity and an increase in the extent of ontogenetic change, by terminal addition. This idea was to be encapsulated by a great adherent of Darwin's concept of natural selection, Ernest Haeckel (1866), who wrote that, "Ontogeny is the brief and rapid recapitulation of phylogeny dependent on the physiological functions of heredity (reproduction) and adaptation (nutrition)." Within the developmental history of a single individual, it was believed, lay the entire evolutionary history of the group. Each animal or plant was perceived as a repository of all that had gone before-an infinite number of evolutionary Russian dolls.

But to Darwin, developmental change was not always unidirectional, leading to more complex forms. Darwin recognized that there were many instances when species had evolved that had undergone less developmental change than their ancestors: "... some animals are capable of reproducing at a very early age, before they have acquired their perfect characters; and if this power became thoroughly well developed in a species, it seems probable that the adult stage of development would sooner or later be lost; and in this case, especially if the larva differed much from the mature form, the character of the species would be greatly changed and degraded." (Darwin 1878, p. 149).

These views presaged ideas that resurfaced in the 1920s and were articulated by the English embryologist Walter Garstang, who argued that vertebrates could have evolved from something as inconsequential as the larva of a tunicate (sea squirt). This tadpole-like juvenile possesses many of the attributes present in adult vertebrates (see below) (Garstang 1928). To get his point across, Garstang was moved to express his ideas about this phenomenon in the Mexican salamander, or axolotl (Fig. 1), in verse:

Ambystoma's a giant newt who rears in swampy waters,

As other newts are wont to do, a lot of fishy daughters:

These Axolotls, having gills, pursue a life aquatic,

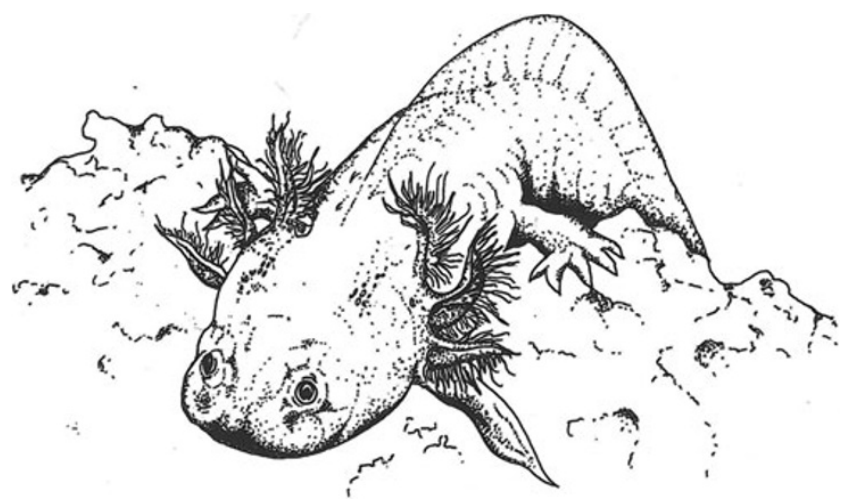

Fig. 1 The classic example of paedomorphosis, the axolotl, or Mexican salamander Ambystoma mexicanum. Reproduced with permission from McNamara (1997)
But, when they should transform to newts, are naughty and erratic.

They change upon compulsion, if the water grows too foul,

For then they have to use their lungs, and go ashore to prowl:

But when a lake's attractive, nicely aired, and full of food,

They cling to youth perpetual, and rear a tadpole brood.

And newts Perrenibranchiate have gone from bad to worse:

They think aquatic life is bliss, terrestrial a curse.

They do not even contemplate a change to suit the weather,

But live as tadpoles, breed as tadpoles, tadpoles all together!

What Garstang argued was that major evolutionary changes (including the evolution of vertebrates themselves) could have arisen from such arrested development and retention of ancestral juvenile traits by descendant adults. Garstang called this paedomorphosis. It was quite the opposite to what Haeckel had suggested, his so-called "recapitulation." With the rise in importance of genetics in the early twentieth century, the role of developmental change in evolution all but disappeared from the literature.

But, in 1977, in his seminal book Ontogeny and Phylogeny, Steven J. Gould argued that not only was developmental change a fundamental aspect of evolution but that the two "forms," paedomorphosis and recapitulation, both occurred: development could slow down or speed up, or be shortened or prolonged, in the descendent relative to the ancestor. This is what generated much of the raw material for natural selection to work on and reflected ideas articulated by Darwin about 120 years earlier, but largely forgotten.

Darwin, though, was not one for using jargon, and I suspect that it is for this reason that his insights have been neglected. Gould was at the forefront of the renaissance in recent years in the relationship between development and evolution. Although subsequently touted as the "new" aspect of evolutionary theory in the guise of evolutionary developmental biology, many of the old ideas that Gould and others espoused in the 1970s and 1980s had been amalgamated under the banner of "heterochrony," a term coined by Haeckel. This formed the basis for the resurgence in interest in the role of developmental change in evolution, which has seen a profusion of papers on developmental genetics to explain many of the changes seen in the phenotype.

Until the 1970s, evolution was thought to center on the classical Darwinian paradigm of natural selection and 
genetics: genes provide the mutations on which natural selection operates. However, the publication of Gould's Ontogeny and Phylogeny highlighted the added significance of developmental changes in evolution. Much of the early research in this field was carried out by paleontologists in the 1980 s, focusing on macroevolutionary changes resulting from heterochrony (see McKinney 1988; McKinney and McNamara 1991; McNamara 1995a, 1997). In the 1990s, an increasing number of biologists began to recognize the importance of developmental change in evolution (Hall 1992).

\section{What Is Heterochrony?}

Heterochrony can be defined as "change to the timing or rate of developmental events, relative to the same events in the ancestor" (Alberch et al. 1979; McKinney and McNamara 1991). All organisms have an ontogeny. This is their life history, from the time of conception until death. While organisms increase in size as they grow, from an initial egg, through larval or embryonic stages, to juvenile and then adult stages, they also change in shape. You, for instance, look very different now from what you looked like when you were born, for the simple reason that many parts of your body have changed in relative shape during your ontogeny. Most organisms have a finite period of growth, which usually ends at the onset of sexual maturity, both size and shape slowing down markedly, or stopping. Within populations of a single species, individuals do not all grow and develop at the same rate or for the same duration; individuals grow at slightly different rates and for slightly different durations. The same holds for many species, where, between closely related species, the main morphological differences arise from variations to the rate and duration of growth.

Certain parts of a single individual may grow for relatively different lengths of time and at different relative rates. Thus, in many vertebrates, for instance, the rate of growth of the head is relatively greater than growth of the trunk or limbs during the embryonic phase of growth, whereas after birth, these postcranial parts undergo a relatively greater amount of growth. Likewise, the formation of finger bones in dolphins can arise from an extension of the period of growth of these parts of the limbs (Richardson and Oelschläger 2002). Thus, slight changes to the rate or duration of growth of various parts of the body during ontogeny can greatly impact upon the appearance of the final adult form. All such changes to the rate and duration of growth of all or part of an organism compared with its ancestor are what define heterochrony.

An organism's growth is determined by its genetic makeup. The genes determine, to a large degree, its morphological, physiological, and behavioral characteristics-so what it looks like, how it functions, and how it behaves. It is now recognized that developmental genes, particularly those regulating embryonic or larval development, play a major role in evolution (Richardson and Brakefield 2003). One group of genes known as homeotic genes controls the timing of expression of growth factors that determine when and where a particular morphological structure starts to develop and its duration of growth. Thus, any changes to the timing of expression of these controlling genes, or the period during which they influence growth, will result in a descendant that can look markedly different from its immediate ancestor.

Any genes that control the regulation of development are now collectively known as "heterochronic genes." Slack and Ruvkun (1998, p. 375) wrote that, "Genes that control the temporal dimension of development, heterochronic genes, can be thought of as the temporal analogs of the homeotic genes, which regulate spatial dimensions (e.g., anterior-posterior, dorsal-ventral axes) during development of metazoans. These pathways generate graded or binary levels of regulatory factors that pattern one axis of the developing animal. Heterochronic genes may be the target of mutations that cause heterochronic change in phylogeny."

Subtle morphological changes therefore occur continually within populations, arising from slight variations between individuals in the duration and rate of growth of the whole organism, or of just particular traits. Within populations, this produces so-called intraspecific variation: heterochronic change being targeted by natural selection. Because heterochrony is so important in providing raw material on which natural selection can operate, it plays a very important role in evolution (McKinney and McNamara 1991; McNamara 1995a, b, 1997; Tills et al. 2011). As well as operating within species at this level of intraspecific variation, it also occurs between sexes (McNamara 1995b); between species, in generating evolutionary trends (McNamara 1982, 1990); and in the evolution of major morphological novelties, such as vertebrates and birds (McNamara 1997; McNamara and McKinney 2005).

\section{Classifying Heterochrony}

Heterochrony can be separated into two different types: paedomorphosis (literally "child-shape") and peramorphosis (literally "beyond-shape"). A descendant organism, whether it be a descendant individual within a population or a geologically younger species, when compared with its ancestor, can show either "less" or "more" growth. Paedomorphosis is the type of heterochrony where there is less growth during ontogeny in a descendant form, compared with its ancestor. The name reflects the fact that descendant adults resemble the juvenile condition of the ancestor. In the other form of heterochrony, the descendant undergoes more 
development and is said to show peramorphosis. Frequently, though certainly not inevitably, paedomorphic forms may be smaller than their ancestor, while peramorphic forms tend to be larger. Paedomorphosis and peramorphosis are not evolutionary processes in themselves but are descriptive terms that describe the appearance of the descendant morphology. They are the morphological (and sometimes behavioral) end result of the operation of a variety of heterochronic processes.

Paedomorphosis and peramorphosis can each be produced by three different, complementary processes: variations in time of cessation of growth, variation in time of commencement of growth, and change in rate of growth (Alberch et al. 1979; McNamara 1986a). Paedomorphosis occurs if the period of growth of the descendant form is stopped prematurely - progenesis (hypomorphosis of Reilly et al. 1997); if onset of growth is delayed-postdisplacement; or if the rate of growth is less in the descendant than in the ancestor-neoteny (deceleration of Reilly et al. 1997) (Figs. 2 and 3). Progenesis will affect the entire organism if premature cessation of growth is caused by the earlier onset of sexual maturity. Like neoteny and postdisplacement, it may, though, also target specific morphological features.

Peramorphosis occurs if the period of growth in the descendant is extended (hypermorphosis), if the onset of growth occurs earlier in the descendant than in the ancestor (predisplacement), or if the growth rate is increased (acceleration). Hypermorphosis, like progenesis, can affect the whole organism when the onset of sexual maturity is delayed, because fast juvenile growth rates will persist for a longer period. Alternatively, hypermorphosis can target just certain traits. Acceleration and predisplacement will affect only specific features, not the entire organism.

While this categorization of heterochrony into these six basic processes appears to have much utility, it has been argued that this presupposes a uniformity of morphological change during ontogeny, which may not always be the case (Rice 1997). It is often possible to compartmentalize ontogeny into discrete growth phases, such as embryonic, infantile, and juvenile growth in mammals, or discrete growth instars in arthropods. Each of these phases can have its own ontogenetic trajectory, which might be at variance with other growth phases. Each can be subjected to its own heterochronic variation, involving extensions or contractions of these phases, or discrete variation in growth rates. This type of intra-ontogenetic heterochrony is called sequential heterochrony (McNamara 2002).

The terminology of heterochrony can be used to describe the appearance of discrete structures formed during ontogeny, such as the number of vertebrae or digits (so-called "meristic" characters) that develop during ontogeny. It can also be applied to the subsequent changes in shape of these structures during growth. These have been termed mitotic and growth heterochrony, respectively (McKinney and McNamara 1991). In many organisms, mitotic heterochrony, particularly that induced by pre- and postdisplacement, can play a very significant role during very early developmental stages. This is due to variations between ancestors and descendants in the timing of onset of development of major morphological features. Neoteny and acceleration, in other words reduced and accelerated growth rates, respectively, will be especially common during later ontogenetic development.

The relationship between size and shape is known as allometry and arises from differential growth rates between different parts of the body or in different axes on the same structure. For instance, as a bone grows, it may become relatively longer and thinner because growth is occurring at a faster rate along one axis than another. Should the relative size and shape of a structure remain the same throughout ontogeny, relative to the organism's overall body size, growth is described as isometric. Although very few organisms grow isometrically (Klingenberg 1998), some individual traits, such as vertebrate skeletal elements, can be isometric. Usually, though, a structure such as a bone will change shape and size relative to the size and shape of the whole organism during ontogeny. If the bone increases in relative size, growth is said to occur by positive allometry.
Fig. 2 The hierarchical classification of heterochrony (based on Alberch et al. 1979)

\section{HETEROCHRONY}

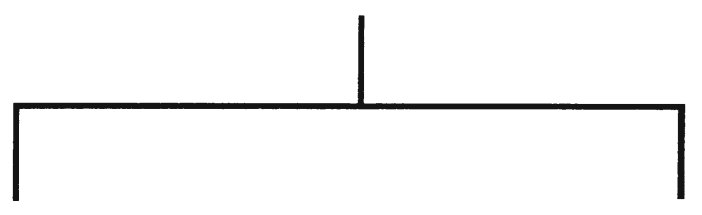

PAEDOMORPHOSIS

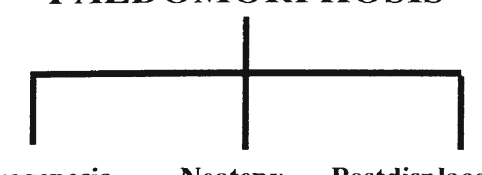

Progenesis Neoteny Postdisplacement (earlier offset) (reduced rate) (delayed onset)

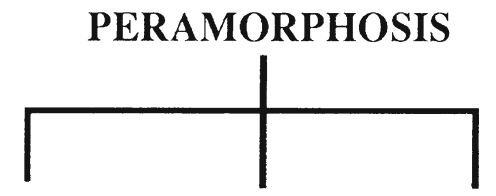

Hypermorphosis Acceleration Predisplacement (delayed offset) (increased rate) (earlier onset) 

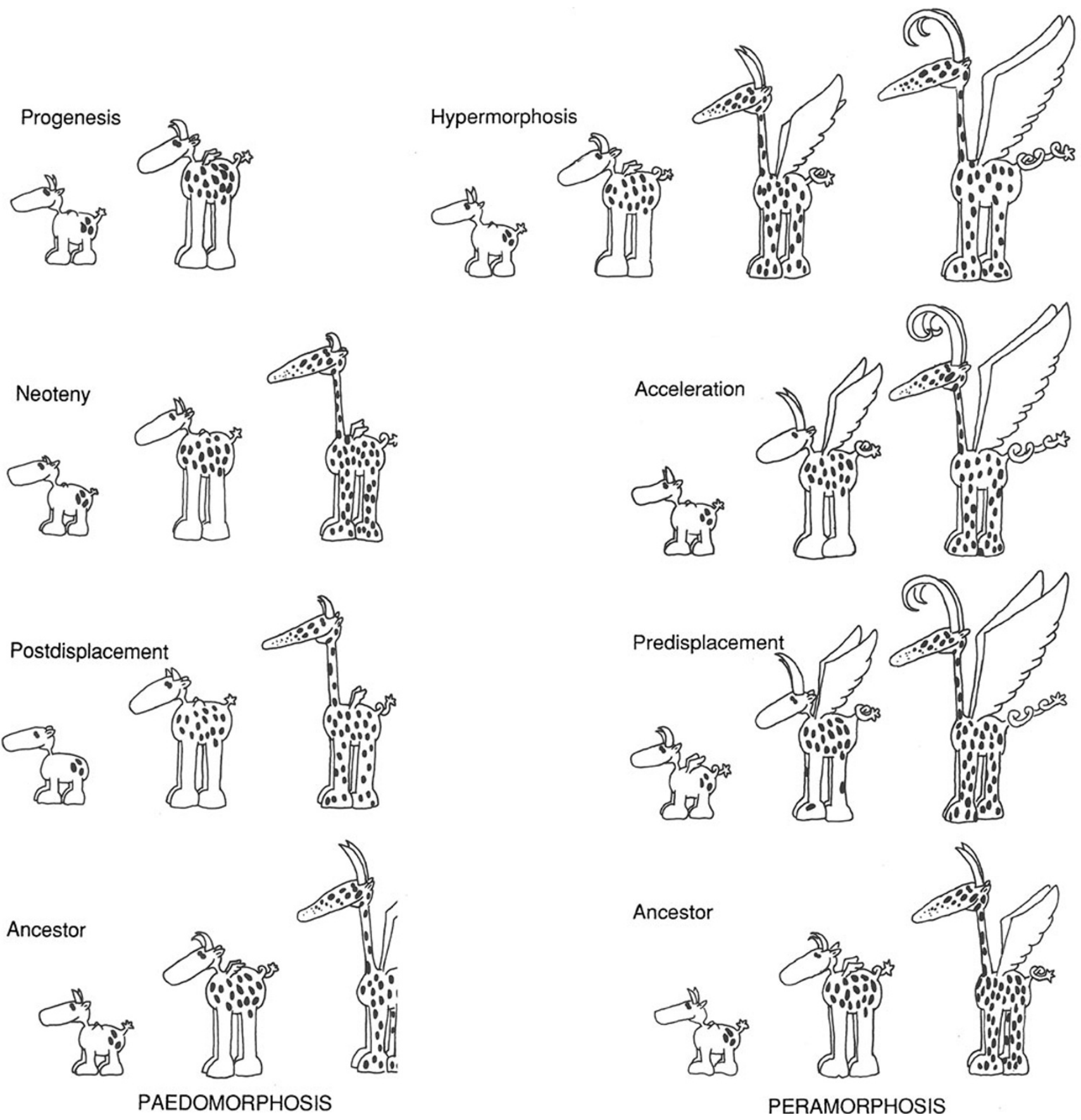

Fig. 3 A hypothetical animal which, during its ontogeny, undergoes a number of morphological changes. Peramorphic descendants develop "beyond" the ancestor; padomorphic descendants retain juvenile ancestral features. In hypermorphosis, growth stops later; in acceleration, the horns and tails grow faster; in predisplacement, the horns and tail

However, if there is a relative reduction in size, growth is said to show negative allometry.

There is a close relationship between allometry and heterochrony because heterochrony involves changes not only in time but also in shape and size. The consequence of changing growth rates (acceleration and neoteny) is to cause start growing earlier. In progenesis, growth stops earlier; in neoteny, the horns and tail grow at a slower rate; in postdisplacement, the horns and tail start their growth relatively later. Reproduced with permission from McNamara (1997)

such allometric changes. Extensions or contractions of the period of growth-in other words, hypermorphosis or progenesis-have the effect of accentuating or reducing the effects of allometric changes. Consequently, those organisms that undergo pronounced allometric change during growth are more likely to generate very different descendant 
adult morphologies if rates or durations of growth have changed.

For example, when the skull of the domestic dog, Canis familiaris, is compared with that of the domestic cat, Felis domestica, the dog skull can be seen to undergo pronounced positive allometric change during ontogeny, particularly by strong growth of the muzzle (Fig. 4). By artificially changing growth rates and timing, a wide range of breeds that vary substantially in cranial morphology have been produced. For instance, tiny dogs like chihuahuas or King Charles spaniels are very paedomorphic, but large Irish wolfhounds are peramorphic (Fig. 5). In contrast, the extent of allometric change is minimal in the domestic cat, so that breeds do not differ greatly in morphology (Wayne 1986). In the natural world, the same effect occurs. Those organisms that produce a wider range of variation because of greater ontogenetic allometric change produce more raw material for natural
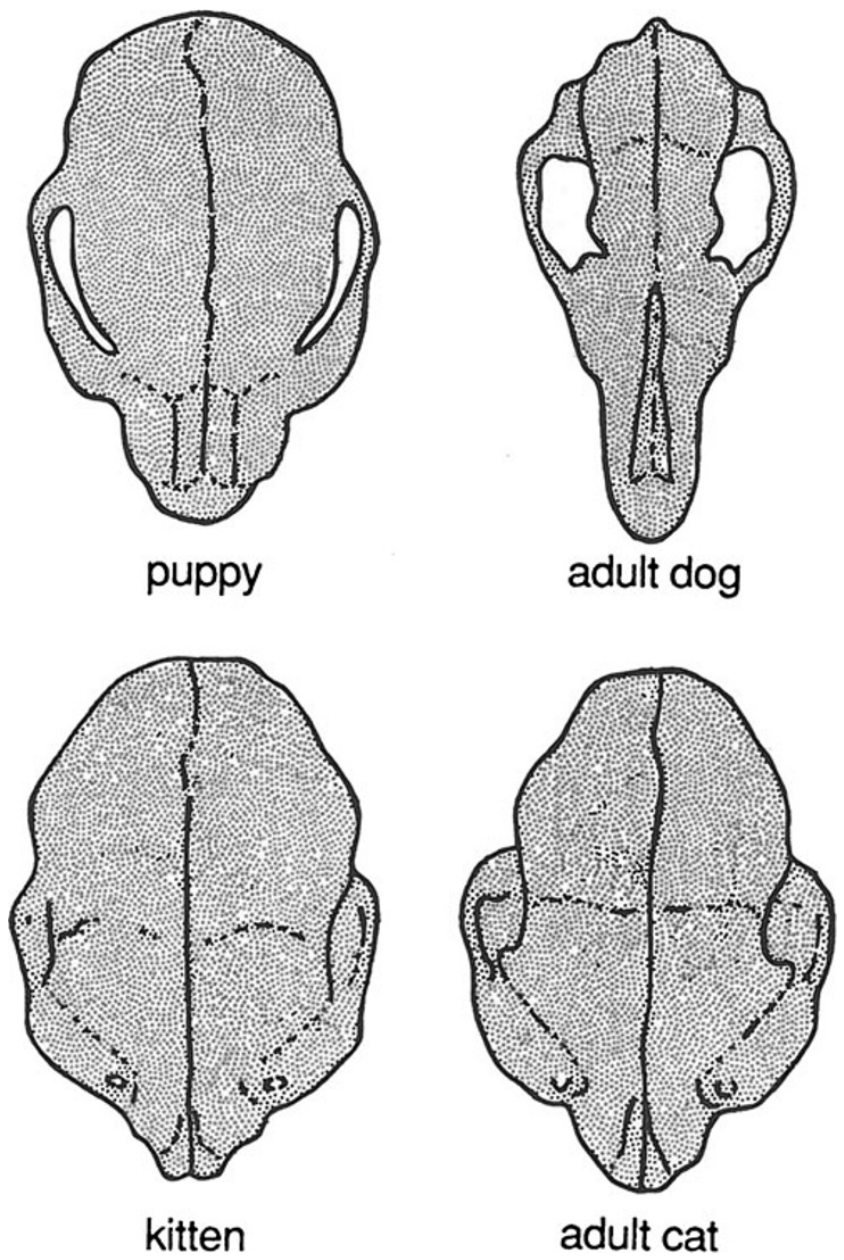

Fig. 4 Proportionate differences in skull shapes of domestic dogs and cats as they grow up. Dogs undergo much greater shape changes than do cats. This explains the greater diversity of skull shapes in different breeds of dogs, compared with cats. Modified and redrawn from Wayne (1986)
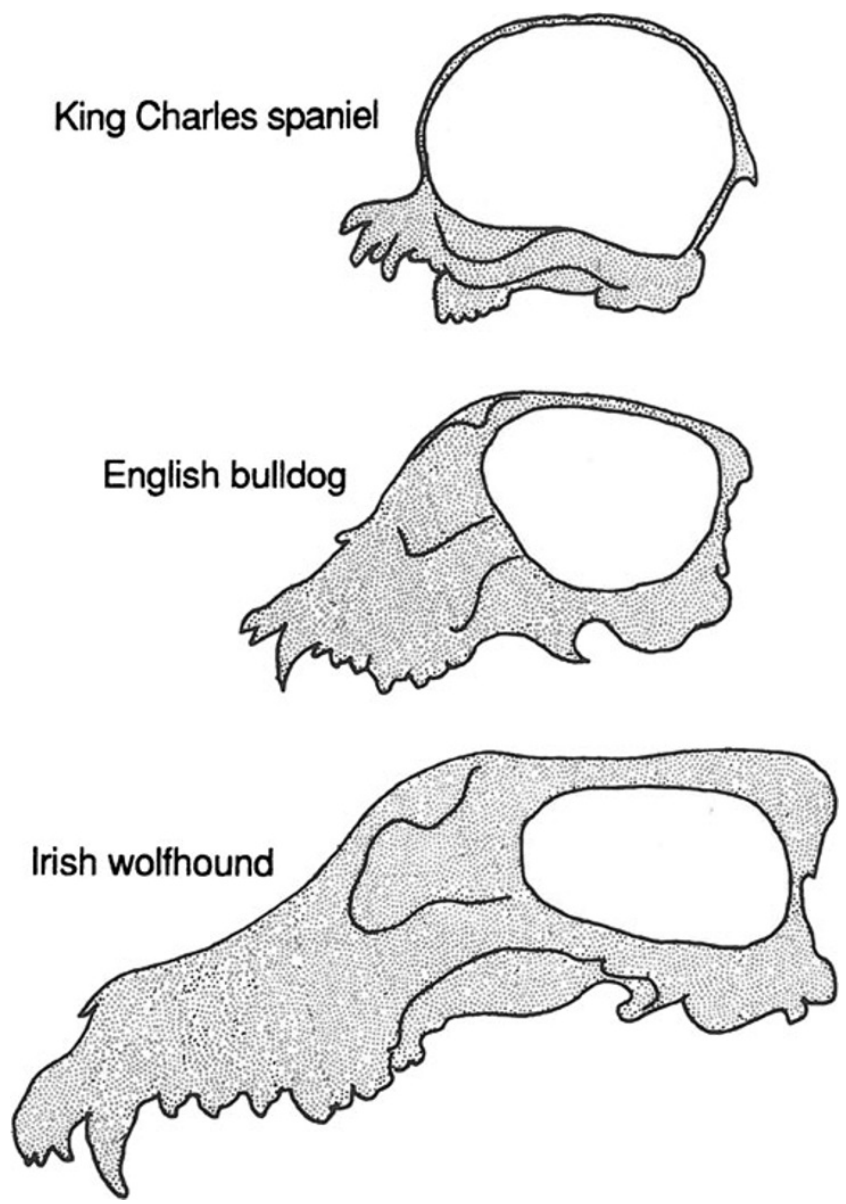

Fig. 5 The large differences in shape of the skull between three different breeds of dogs, shown in longitudinal section: the "most" paedomorphic at the top, the "most" peramorphic at the bottom. The shorter the face, the more vaulted the cranium. Modified and redrawn from Wayne (1986)

selection, leading to the evolution of a wide range of descendants.

It may be trifle hard to imagine but your fluffy little Pekingese dog peering at you with doting eyes is really a wolf. This is because, as one of the numerous breeds of domestic dog (many unwittingly selected for by humans for particular heterochronic traits), it "evolved" from a wolf. All the traits present in the first known domestic dogs, which date back to at least 30,000 years (Germonpré et al. 2009), occur in puppies of wolves: shortened muzzles; steeper, wider foreheads; and smaller body size (Fig. 6). Thus, domestic dogs are essentially paedomorphic wolves (Morey 1994). But Mesolithic man was unlikely to have been selecting for these traits. He was more likely to have been selecting aspects of juvenile wolf behavior. Such more amenable juvenile behavior is more likely to have put wolf pups in contact with humans. Socialization in dogs is best developed when they are between three and 12 weeks old, at a time when primary bonds are formed. Those that fail to 
Fig. 6 Evolution of the domestic dog from the wolf by paedomorphosis, showing the similarity of the skull of early domestic adult dogs with that of juvenile wolves. Modified and redrawn from Morey (1994)

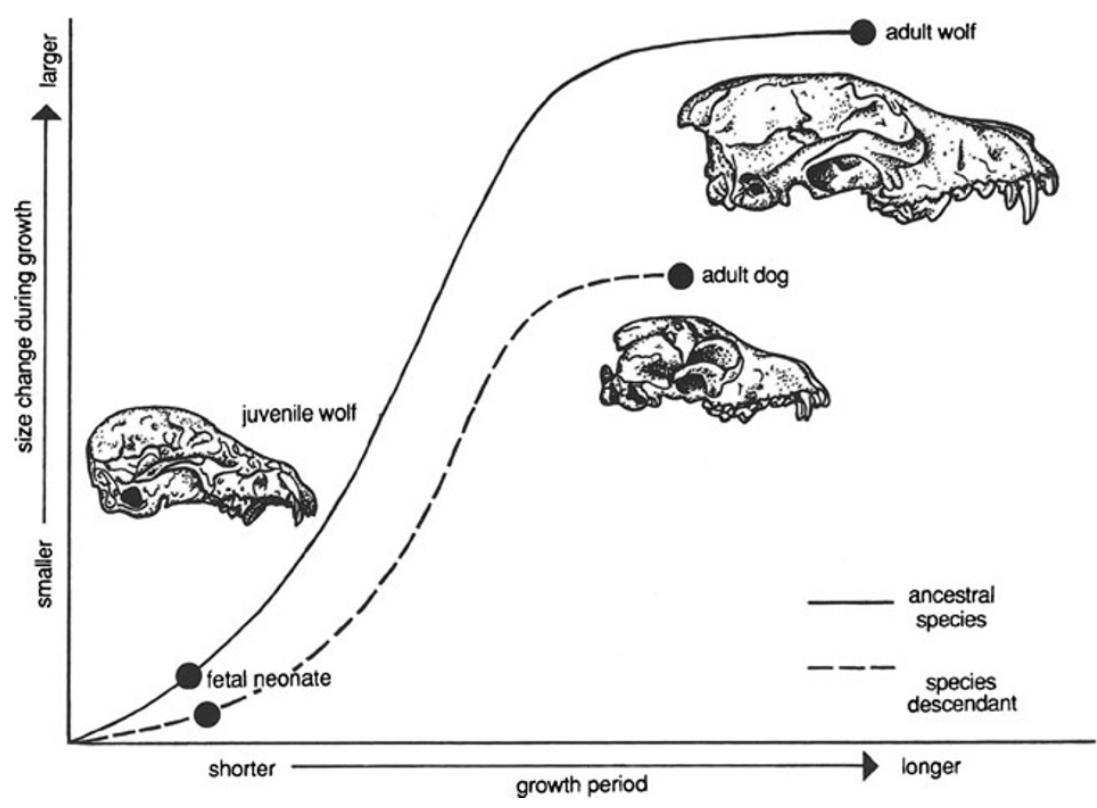

bond with humans are likely to have been driven away or killed.

\section{Identifying Heterochrony}

Recognizing the effect of heterochronic processes requires knowledge of ontogenetic information from both ancestral and descendant forms. Whereas many ontogenetic changes will be species specific, there are many general changes that occur within particular groups of higher taxa, so that even if the ontogeny of the descendant and presumed ancestral form are not known in detail, a number of inferences concerning likely occurrence of heterochrony can still be made. Many examples of heterochrony have been documented in the fossil record (McNamara 1995a, 1997). When dealing with fossil material, two of the factors involved in heterochrony, namely shape and size, are always available. As such, it is possible to assess whether a particular species is either peramorphic or paedomorphic. However, understanding which processes have caused the heterochrony can be difficult when dealing with fossil material, as accurate details of the duration of rate of growth are often unknown.

However, one group that can provide such information is dinosaurs. A number of studies have been made describing growth rates and time of onset of sexual maturity and cessation or reduction in growth in dinosaurs (McNamara and Long 2012). For instance, studies of bone microstructure in a range of dinosaurs show that periodic, possibly seasonal, growth is reflected in growth lines in the bone (see below). This allows "real"-time information to be obtained from such fossil material, making it possible to produce relatively accurate inferences of the type of heterochronic processes operating in extinct species.

Many paleontological studies have used size as a proxy for time - that is, if one species is smaller than another, it is assumed that it grew for a shorter period of time. Consequently, assumptions are made that, for example, a descendant that is smaller than its ancestor and shows paedomorphic morphological characteristics, ceased growing at an earlier age and therefore arose by progenesis. So, for instance, the small late Cretaceous tyrannosaurid dinosaur, Maleevosaurus, which was "only" five meters long, is smaller than its presumed ancestor but also possesses some paedomorphic features. As I have pointed out, paedomorphosis can be caused by neoteny or progenesis. Either process could explain paedomorphosis in these smaller tyrannosaurs. However, studies in other groups of organisms show that neoteny tends to target only specific structures, not the whole organism. In the case of Maleevosaurus, although progenesis is more probable, in the absence of actual growth rate data, it is not possible to determine the process precisely.

While it may often seem to be relatively straightforward to identify heterochrony, such as a reduction or increase in number of segments in adults of different species of trilobites (Fig. 8), identifying subtle allometric changes between ancestor and descendant may be less obvious. One technique used in a number of studies is morphometrics. Here, fixed positions (known as landmarks) on, say, a trilobite head, are recorded for different ontogenetic stages. These are then compared with the same positions on a presumed descendant species. Subtle variations in growth rates of parts 
of the structure will occur by heterochronic processes that can be identified (e.g., Webster et al. 2001). Mitteroecker et al. (2005) have applied this technique to a study of the evolution of cranial growth in chimpanzees. However, they caution against the use of single characters when trying to interpret heterochrony. Rather, they argue (Mitteroecker et al. 2005, p. 255), "...that a single morphological characterization, descriptions in terms of bigger/smaller or more/less of something, should generally not be subjected to heterochronic interpretation, nor should single ratios. Multivariate analysis circumvents this theoretical problem when heterochrony is defined as multivariate ontogenetic scaling along a common ontogenetic trajectory."

\section{Relative Frequency of Heterochrony}

It has been argued that theoretically, paedomorphosis and peramorphosis should occur with roughly equal frequencies (Gould 1977). Yet studies of heterochrony in the fossil record suggest that this may not always be the case. Amphibians show a preponderance of paedomorphosis (McNamara 1988), which may be related to their large cell size, causing a reduced rate of cellular division (McNamara 1997).

Paedomorphosis has occurred many times in frogs, for example, resulting in the development of many miniature species. The 29 smallest species (with the smallest having an average body length of just 7.7 millimeters) are spread across five families and 11 genera (Rittmeyer et al. 2012). As well as very reduced size, these frogs have reduced fecundity and show paedomorphic traits of reduced ossification and lack of digits. Moreover, many of these frogs are direct developers, lacking a tadpole stage, and as such form a distinct ecological guild (Rittmeyer et al. 2012).

In contrast, peramorphosis may have been more frequent in dinosaurs, in particular being a major contributing factor to the evolution of very large body size (McNamara and Long 2012). Many types of dinosaurs, such as sauropods, ceratopsians, theropods, and ornithopods, show not only trends toward increased body size but also the attainment of larger, more complex morphologies by peramorphosis (Fig. 7).

Heterochrony played a very important role in the evolution of trilobites. This is thought to have been due to their developmental systems having been poorly constrained when they first evolved in the Early Cambrian (McNamara 1986b). This is shown by the high variability in segment number, both within and between species in these earliest trilobites. Through Cambrian times, there is progressive improvement in the trilobites' developmental systems, so that by post-Cambrian times, many families of trilobites have fixed thoracic segment number. Moreover, documented cases indicate that in Cambrian trilobites, natural selection favored paedomorphic processes more than peramorphic ones (Fig. 8). However, greater morphological diversity of post-Cambrian trilobites may have been facilitated by a shift to selection for mainly peramorphic processes.

\section{Heterochrony and Sexual Dimorphism}

Many species of animals exhibit sexual dimorphism. This can take the form of differences in average maximum size

Fig. 7 Peramorphic evolution of protoceratopsian dinosaurs. Reproduced with permission from McNamara (1997)

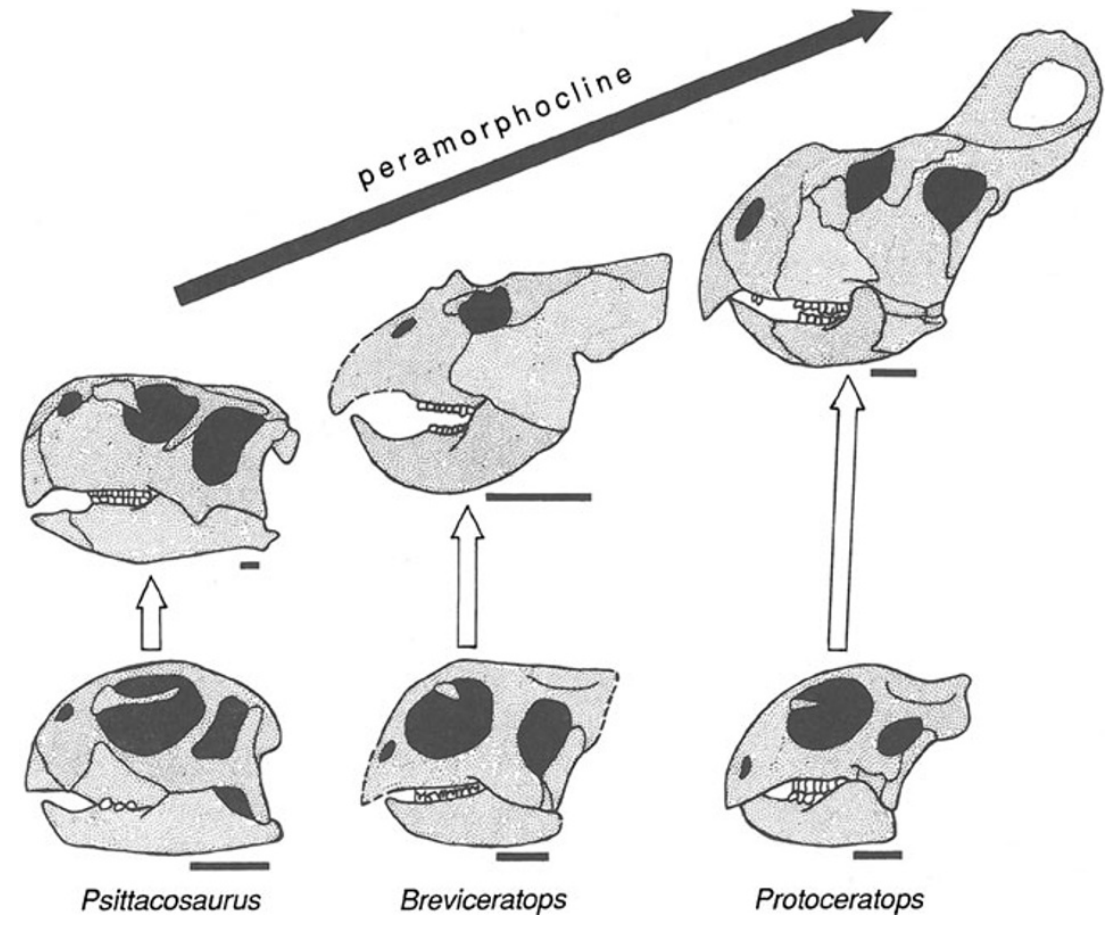


Fig. 8 Paedomorphic evolution of species of the oryctocephalid trilobite Arthricocephalus from the Early Cambrian of Guizhou Province, China. Numbers refer to thoracic segments. Modified from McNamara et al. (2006)

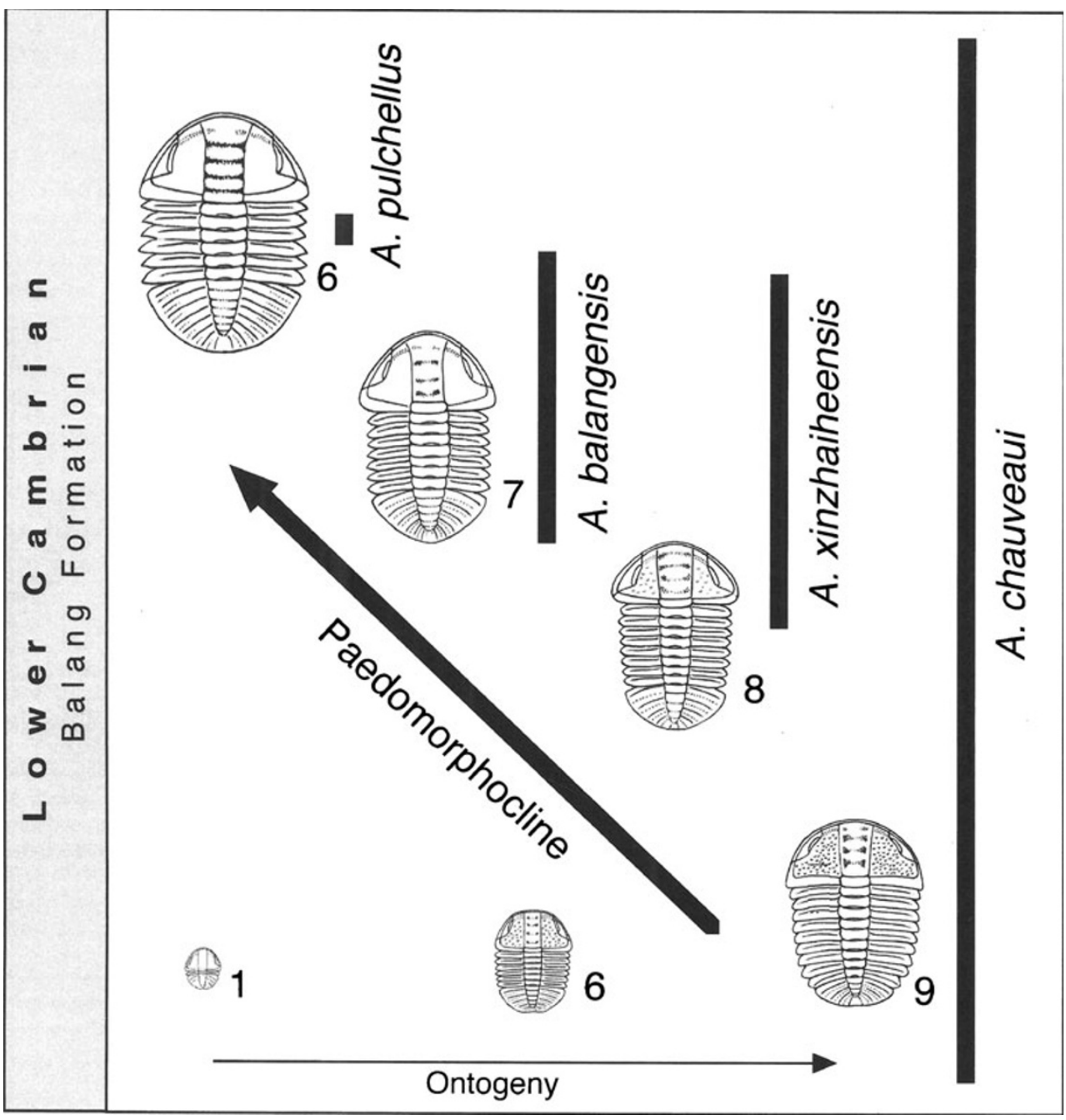

between males and females and/or differences in morphological features. This size and morphological variance arises from either variations in growth rates or differences in the relative times of onset of sexual maturity; in other words, it arises from heterochrony (see, for example, the work by Denoël et al. (2009) on European newts). A relative modest example occurs in the Indian Ocean blue boxfish, Strophiurichthys robustus, where both male and female juveniles have a diamond-shaped body and a body pattern dominated by spots. During their development, males change their body shape, so that it becomes more oval in outline. This probably reflects a change in their degree of maneuverability when swimming. Their body pattern also changes from spots to a series of elongate wavy patterns. The females, however, retain the juvenile features of diamond-shaped body and body pattern of spots (Fig. 9). Thus, the females can be regarded as paedomorphic, compared with the males (McNamara 1995b).

A more extreme case occurs in deep sea angler fish, such as Photocorynus, where the male is very much smaller than the female, retains early juvenile morphological features, and lives parasitically attached to the female's head (McNamara 1997, p. 116). Perhaps one of the most extreme examples of sexual dimorphism is in eulimid gastropods. These animals live parasitically within holothuroids (sea cucumbers). The males are exceedingly reduced in size and complexity and themselves live within the body of the female where they live attached to a special receptacle and grow to be little more than a testis (Fig. 10). Such extreme dimorphism, of a smaller, paedomorphic male living within or upon a female, is not that uncommon in marine invertebrates, examples having been documented in a number of groups of mollusks and echinoderms. Many examples of less extreme sexual dimorphism brought about by heterochrony have been described in primates, in particular in macaques (German et al. 1994).

Many species of beetles develop very enlarged front legs, mandibles, horns, or other protruding structures on their head. These are the product of positive allometry and so are more well developed in larger individuals that have grown for longer. Frequently, males grow for longer periods than females during development and end up possessing these prominent structures while females do not (McNamara 
Fig. 9 The adult female of the blue boxfish Stropiurichthys robustus is paedomorphic compared with the male, resembling the juvenile in body shape and body patterning. Reproduced with permission from McNamara (1997)
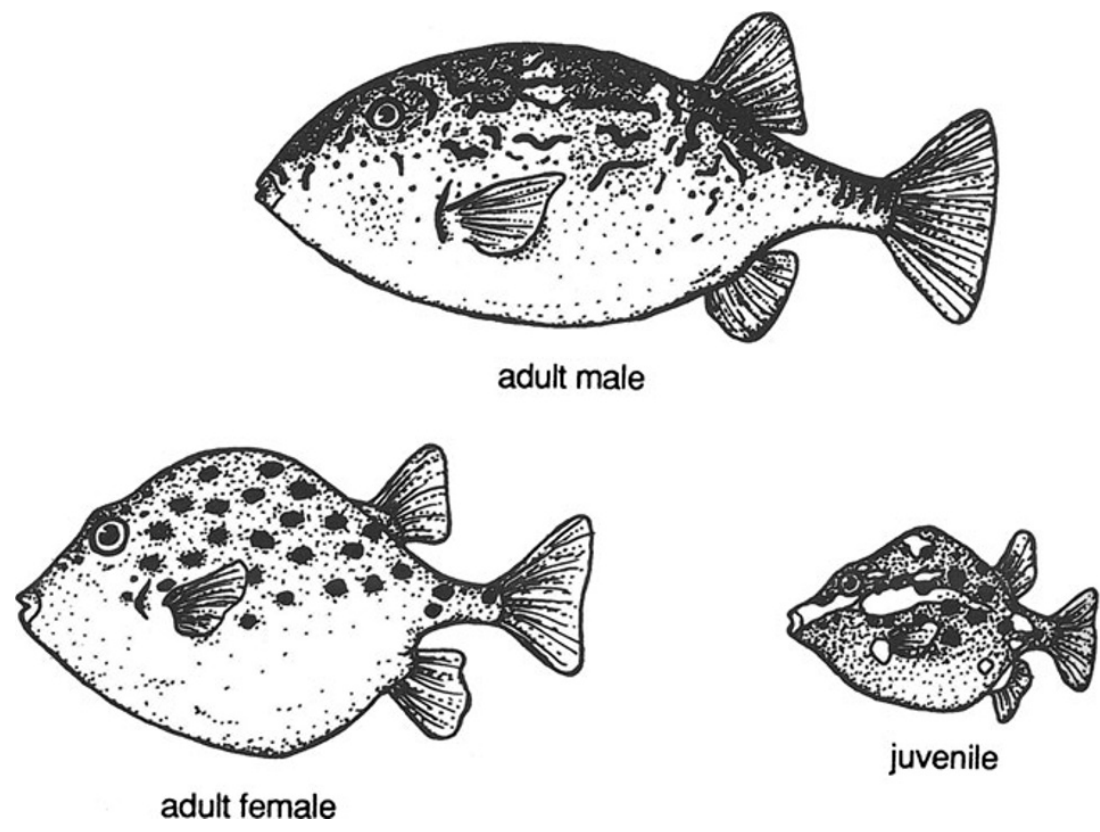

1995b). Sometimes, even within a single sex, this character may be dimorphic. Cook (1987) showed that one of the sexual dimorphic characters in the dung beetle Onthophagus ferox are the horns, which occur on the males but not the females. Even here, there are two distinctive male morphs,

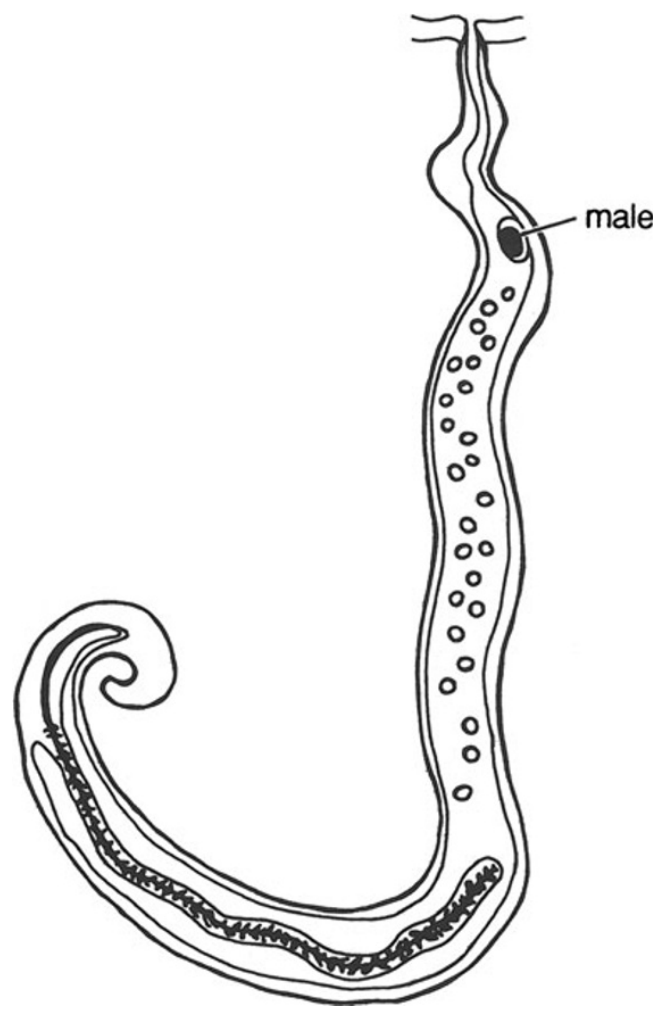

Fig. 10 Extreme sexual dimorphism in the parasitic gastropod Thyonicola living within a holothuroid (sea cucumber). The male is extremely reduced and is parasitic within the female, spending its entire life in a special receptacle, fertilizing the female one with a small body size and lacking horns, the other larger and with horns. Such male dimorphism, arising from allometric scaling of horn size, occurs in a number of other beetles and shows that such horns form due to differences in either growth rates or timing of cessation of growth, in conjunction with strong positive allometry in the structure. A similar example occurs in the New Zealand tree weta Hemideina crassidens (Kelly and Adams 2010), two male morphs differing in head weaponry, which is reduced in females, the differences rising from variations to duration of growth during ontogeny.

How big a beetle grows and thus whether or not the male develops large structures are partly dependent on availability of food. Brown and Lockwood (1986) found that in the forked fungus beetle Bolitotherus cornutus, individuals that as larvae feed on more nutritious fungi emerge as adults at a larger size and attain a larger adult size. Consequently, the males form relatively larger horns than individuals feeding on less nutritious fungi. Moreover, even the developmental state of the fungus can affect the beetle's growth rates. So beetle larvae feeding on younger fungi grow faster and attain a larger body size than those feeding on older fungi that are less nutritious.

\section{Heterochrony and the Evolution of Large Body Size}

The pattern of evolutionary trends of increased body size that occurs very frequently in the fossil record is known as Cope's rule (Hone and Benton 2005). It is probable that peramorphosis is a prime factor in generating such increases in body size, either by hypermorphosis or acceleration (McNamara 1997). Studies of lineages of Jurassic bivalves 
and ammonites (Hallam 1975) demonstrated that many show trends to increased body size. Similar patterns occur in foraminifers, primates, and other mammals (McKinney in McNamara 1990) and in pterosaurs (Hone and Benton 2007).

The effect of peramorphosis in driving trends of increased body size is best shown by dinosaurs (McNamara and Long 2012). The peramorphic trends of increases in body size in sauropods, ceratopsians, theropods, and ornithopods produced not only increases in body size, but also increased complexity of many morphological features (Fig. 7). Recent research on bone microstructure has shown that many juvenile dinosaurs experienced very rapid growth rates (Padian et al. 2001; Sander and Klein 2005), implying that acceleration was the process responsible for the attainment of the peramorphic features. However, studies of theropod growth patterns support the argument that the evolution of very large body sizes of many dinosaurs may have occurred by a combination of both acceleration and hypermorphosis.

In a study of tyrannosaurid theropods, growth rate data for four genera, Albertosaurus, Gorgosaurus, Daspletosaurus, and Tyrannosaurus, were compared (Erickson et al. 2004). Albertosaurus and Gorgosaurus are the smallest, Daspletosaurus a little larger, and Tyrannosaurus appreciably the largest. Using bone histology, it was calculated that the body size of Tyrannosaurus was about 5.5 tons. It grew fastest for about the first four years of its life, when it was adding about two kilograms per day. Growth slowed after that until full maturity was reached when the dinosaur was about 18.5 years old.

The other three theropods were relatively smaller, reaching maximum body sizes of about one ton in Gorgosaurus and Albertosaurus, and about 1.5 tons in Daspletosaurus. Their maximum growth rates also persisted for up to about four years but were much less than in Tyrannosaurus rex, being about one-third to one-half kilogram per day. These genera would have also become mature at a younger age than $T$. rex, between about 14 and 16 years. So not only was $T$. rex growing much faster (acceleration) than other tyrannosaurids, but it also had a delayed offset of growth (hypermorphosis). When these four tyrannosaurids are compared with geologically older theropods, such as Syntarsus, the earlier forms became mature at the much younger age of about four years and had a maximum growth rate of only nine kilograms per year (Chinsamy 1990). It is significant that the evolution of gigantism in other reptiles, notably crocodiles and lizards, was attained only by hypermorphosis (Erickson et al. 2003).

\section{Heterochrony and Developmental Trade-Offs}

Most organisms are not just paedomorphic or peramorphic but a mixture of traits that evolved by both peramorphic and paedomorphic processes. Such a mixture is known as dissociated heterochrony. It has been suggested that there may be a relationship between the peramorphic and paedomorphic traits, such that the paedomorphic traits may be developmental trade-offs for the peramorphic features (McNamara 1997). For instance, peramorphosis and size increase are often associated with the development of some paedomorphic traits. Evolutionary trends toward increased body size result in the organisms being required to input a greater amount of energy to attain the larger body and the accompanying more complex morphological featurers than in ancestral forms. This can be achieved by trade-offs, with selection pressure preferentially favoring some structures.

A classic example of a developmental trade-off is the dinosaur T. rex which as well having a huge body, possessed extremely reduced paedomorphic forelimbs and a hand with only two digits. This paedomorphic forelimb of $T$. rex is very unlikely to have had any adaptive significance but may have been a developmental trade-off for the evolution of its large body size, particularly the hind limbs and the head. The peramorphic development of a large body size in combination with increased complexity and size of the skull and hind limbs is offset by the paedomorphic reduction in the forelimbs and digits.

This phenomenon has also been recognized in hominid evolution, where it is known as the "expensive tissue hypothesis" (Aiello and Wheeler 1995). Here, while selection has favored larger body size and brain in humans by hypermorphic extension of the growth period, the trade-off to evolve metabolically hungry brain tissue is the reduction of the size of the gut, the lower jaw, and teeth. Likewise, in large ratite birds such as the ostrich and emu, trends to a large body size and very large hind limbs are offset by a paedomorphic reduction in the wings and a flightless habit.

\section{Heterochrony and Evolutionary Novelties}

Heterochrony has often been suggested as playing a significant role in the evolution of major evolutionary novelties (McKinney and McNamara 1991; Jablonski 2000; McNamara and McKinney 2005). In the 1920s, Walter Garstang suggested that vertebrates evolved from a tunicate-like larva by paedomorphosis (Garstang 1928). Adult tunicates, or sea squirts, are jelly-like organisms that attach to a hard substrate such as a rock. The larvae, though, have many of the attributes one would expect from a vertebrate: a notochord, gill slits, and a postanal propulsive tail. Garstang suggested that attainment of sexual maturity at a very early growth stage would have "frozen" the tunicate in its larval form, in which it could reproduce. 
The reason that early maturation, or progenesis, has been proposed as potentially the most important heterochronic process to produce evolutionary novelties (Gould 1977) is that progenesis involves not just the pronounced morphological disparity between ancestor and descendant due to the much earlier offset of growth, but selection may also target the life history strategy of precocious maturation (see below) rather than morphology itself. However, other heterochronic processes, such as neoteny and hypermorphosis, may also play a significant role in macroevolution. A study of the largest-ever terrestrial lizard, the Australian Pleistocene varanid Varanus (Megalania) prisca, has shown how it evolved by hypermorphosis (Erickson et al. 2003). This giant reptilian carnivore, measuring about seven meters in length and weighing more than half a ton, was more than twice the length of any living varanid. It reached its enormous size by delaying its time of onset of maturity by three to four years compared with other varanids.

Limb loss in snakes and whales also demonstrates the importance of paedomorphosis in the evolution of morphological novelties. Here again, rather than progenesis, the process is more likely to have been neoteny or postdisplacement, or perhaps a combination of the two. The apparent dominance of paedomorphosis in the evolution of major morphological novelties is due, in part, to the greater degree of morphological difference between very early embryonic and adult forms than between adult morphologies that have been accelerated or extended by hypermorphosis. Having said that, however, it may be that peramorphic changes very early in development, such as an earlier onset of growth of specific morphological traits, might play as significant a role in the formation of morphological novelties as paedomorphic delays.

Sometimes, the evolution of a major new group of organisms can be attributed to dissociated heterochrony, with the evolution of critical paedomorphic and peramorphic traits combining to produce a radically different organism. A classic example of this is the evolution of birds from dinosaurs. It is now known from the superbly preserved Early Cretaceous dinosaurs of Liaoning in China that many small dinosaurs possessed feathers. It is feasible that feathers were also present not only on some small adult dinosaurs but also on juveniles of larger forms. If this was the case, then the small-bodied dinosaurs, such as the feathered Sinosauropteryx and Caudipteryx, can be interpreted as paedomorphic dinosaurs. Similarly, the retention of feathers in birds can be considered as being by paedomorphosis. Early birds that evolved in the Late Jurassic to Early Cretaceous show other paedomorphic traits, such as reduction in some digits; a small body size; retention of a number of unfused bones; a gracile, elongate skull; large orbit; and a relatively large brain case. However, a critical feature of early birds, such as Archaeopteryx, is the possession of greatly enlarged forelimbs that enabled the development of flight. These formed by peramorphic processes targeting these particular skeletal elements.

\section{Heterochrony and Evolutionary Trends}

Heterochrony is also important in the generation of evolutionary trends (McNamara 1982, 1990). This is because the link between evolutionary trends and heterochrony is due to the inherent directionality in evolutionary trends that also occurs in organisms' development. For an evolutionary trend to become established, selection of either more and more paedomorphic or peramorphic traits must take place along an environmental gradient. For instance, in the aquatic environment, this could be from deep to shallow water or from coarse- to fine-grained sediments. In the case of evolutionary trends generated by heterochrony in dinosaurs situated in the terrestrial environment, the agents of selection are harder to quantify but may relate to "arms races" between predators and prey: as a prey species evolves a larger body size to combat the effect of predation from a particular source, so selection will favor larger predators.

Any evolutionary trend that shows increasingly more paedomorphic characters between ancestors to descendants is called a paedomorphocline. If increasingly more peramorphic descendants evolve, it is called a peramorphocline (McNamara 1982). The driving force behind such heterochronically driven trends is generally either competition or predation pressure. When the trend forms by competition, the ancestral form will persist and force selection in a single direction, away from the ancestral species. However, selection brought on by predation pressure will produce anagenetic evolutionary trends, where ancestral species are progressively replaced by the descendant forms and do not persist. Examples of paedomorphoclines have been described in Cenozoic brachiopods (McKinney and McNamara 1991), where the environmental gradient was from deep to shallow water (Fig. 11); in trilobites (McNamara 1986a); and in ammonoids (Dommergues 1990; Korn 1995; Gerber 2011). The best examples of peramorphoclines are in dinosaurs (McNamara and Long 2012).

\section{Heterochrony and Life History Strategies}

A close relationship exists between life history strategies and heterochrony. Life history strategies include a number of factors: size at birth; growth rate; age at maturation; body size at maturity; number, size, and sex of offspring; and lifespan. Many of these factors are determined by heterochrony. There have been numerous attempts to categorize life history traits. These have met with limited success. The 
Fig. 11 Over a period of about 60 million years, the Australasian brachiopods Tegulorhynchia and Notosaria have become increasingly paedomorphic, forming an evolutionary trend in the form of a paedomorphocline. The retention of more paedomorphic features has allowed successive species to colonize increasingly shallow water. The earliest forms inhabited deep, quiet water. The species at the end of the paedomorphocline inhabits the intertidal zone. Reproduced with permission from McNamara (1997)

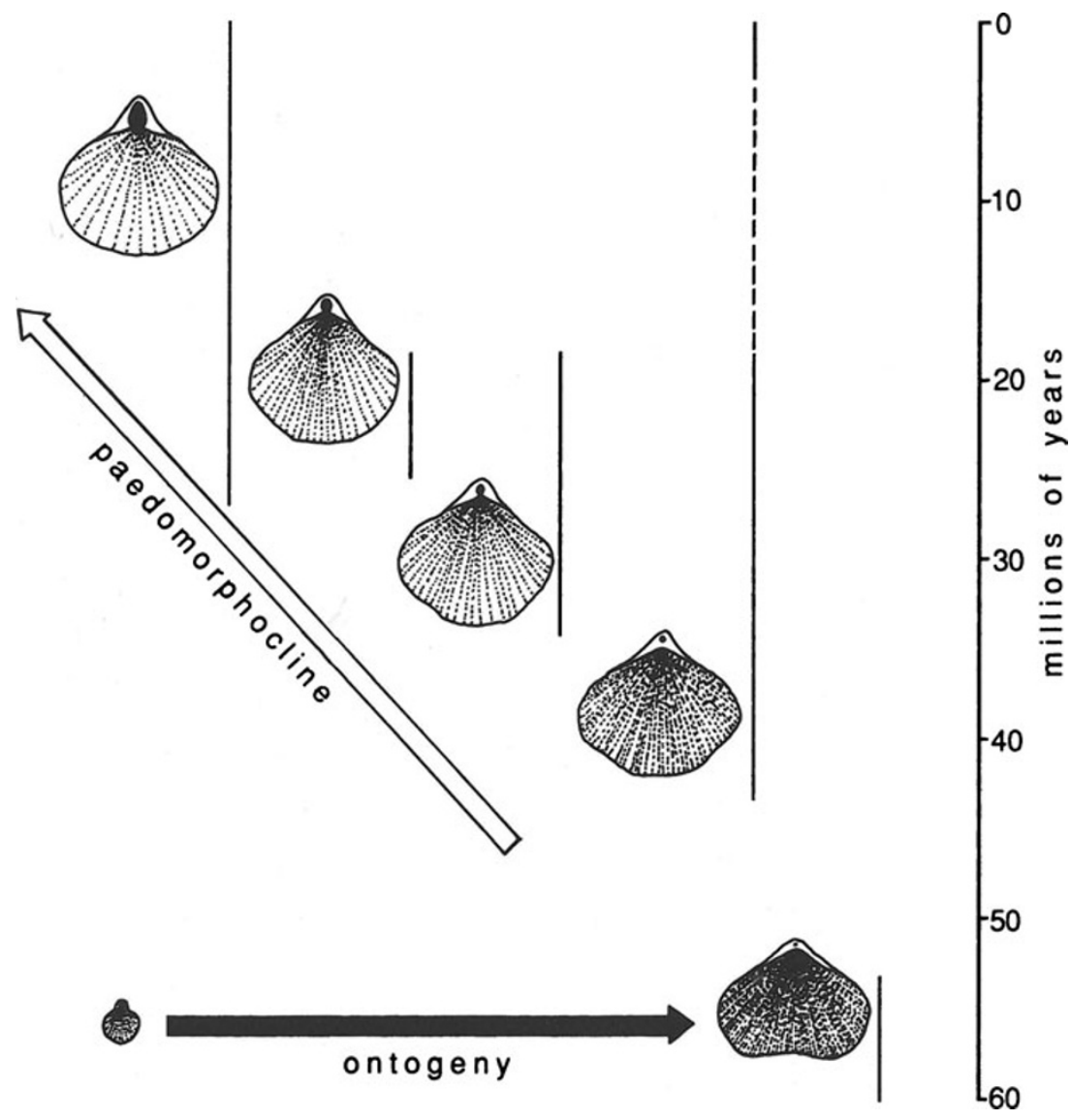

most well known is the " $r-K$ continuum." This describes both environments and life history traits of the organisms that inhabit these environments. Despite the $r-K$ continuum model being an oversimplification of life history strategies, it appears to offer some applicability at higher taxonomic levels as well as containing many elements that fit with current ideas on density-dependent regulation, resource availability, and environmental fluctuations (see Reznick et al. 2002 for a review of the controversy over the use of the theory).

The " $r$-selected" end of the continuum consists of unpredictable, often ephemeral, environments. As a result, selection pressure for organisms that inhabit such environments favors those that mature rapidly, have short life spans, and have small body size. These are all features of progenesis. Organisms that are $r$-selected typically produce large numbers of offspring. At the other end of the $r-K$ continuum are " $K$-selected" organisms that occupy predictable, stable environments. These organisms typically have a relatively delayed onset of reproduction, long life span, and consequent large body size, all features of hypermorphosis. Such organisms produce few, large offspring. In addition to being generated by progenesis, $r$-selected characteristics may also be produced by acceleration (McKinney and McNamara 1991). Moreover, many $K$-selected organisms appear to

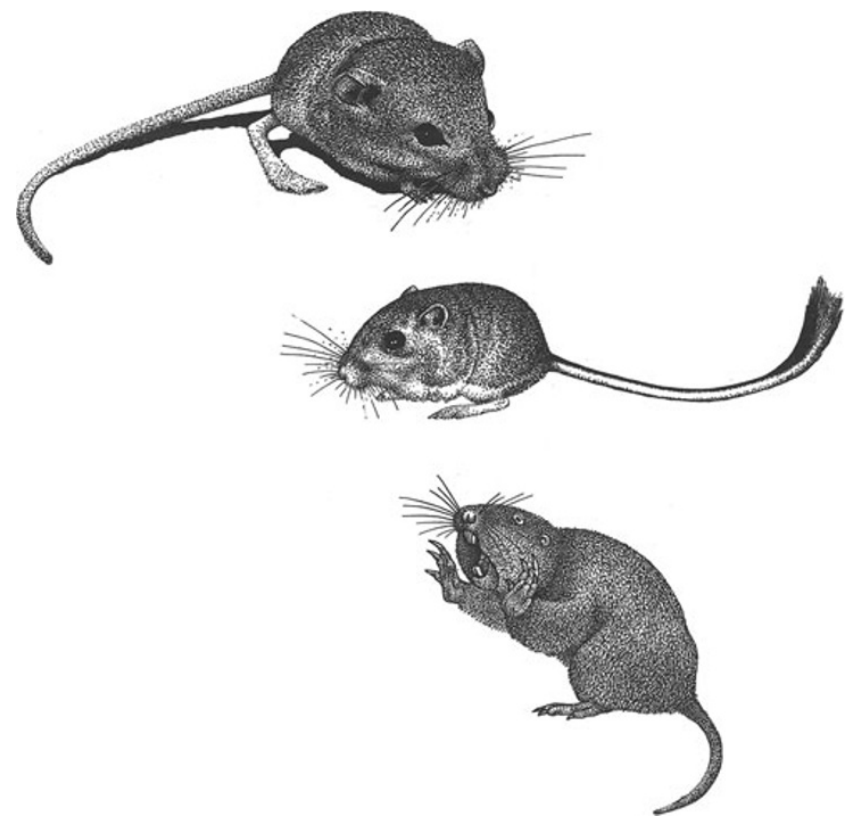

Fig. 12 The tiny progenetic kangaroo Microdipodops (top) has a body length of just 75 millimeters. The kangaroo rat Dipodomys (middle) is neotenic, with a body length of about 200 millimeters. The pocket gopher Orthogeomys (bottom) is a much larger hypermorphic rodent that has a body length of about a third of a meter. Reproduced with permission from McNamara (1997) 
show some traits that evolved by neoteny, as well as hypermorphosis, so a reduction in growth rate rather than a delay in offset of maturity.

A good example of the role of heterochrony in the evolution of life history strategies occurs in the kangaroo mouse, kangaroo rat, and pocket gopher that live in North America (Fig. 12). Natural selection did not favor the length of their tail, color of their fur, nor size of their eyes, but the life history strategy of the animals. It used to be argued that the evolution in these heteromyid rodents of morphological features such as big hind feet, large eyes, and long tail was an adaptation to a life in the desert, the large head counterbalancing the rodent as it hopped purposefully through the cool desert nights on large sand-paddle feet, hunting for food using its big eyes and steering with the large rudderlike tail (McKinney and McNamara 1991).

However, research by Hafner and Hafner (1988) indicates that the small size and paedomorphic traits of the adult kangaroo mouse Microdipodops were due to selection for the earlier maturation, producing a body length of just eight centimeters. By contrast, the adult of the larger kangaroo rat Dipodomys evolved by a reduction in rate of development. This genus has a longer life span, slower development, larger body size (20-centimeter length), longer gestation period, and smaller litters than the mouse. These are classic $K$-selected features. A third, related rodent, the pocket gopher Orthogeomys, grows to about a third of a meter in length. But instead of retardation of growth, there has been a hypermorphic extension of the growth period, producing a robust body form.

Extrinsic factors such as climate change can have a direct impact on life history traits in some types of plants by inducing heterochronic changes in descendants. Studies of evolutionary change in the annual plant Brassica collected in California before and after a five-year drought found that these drought conditions produced many changes in descendant life history traits that relate to changes to timing of development (Franks and Weis 2008). These include a change to earlier flowering time, as well as longer duration of flowering. These descendants also had thinner stems and fewer leaf nodes at flowering time than ancestral forms, showing that the result of the drought was selection for plants that flowered at a smaller size and at an earlier ontogenetic stage instead of selecting for plants that just developed more rapidly.

\section{Conclusions}

For the last half-billion years, this Earth has been populated by an astounding menagerie of organisms. Millions of species have come and gone - they have evolved; they have gone extinct. What has enabled this great panoply of forms to evolve has been the inherent flexibility within the genomic systems of organisms that has enabled subtle variations to take place within populations in the rate of growth and variations in the timing of initiation and cessation of growth. Controlled by critical heterochronic genes that switch growth on and off at different times and the genes that control the growth hormones that dictate the extent to which particular traits will develop, evolution of morphology and consequently, behavior, is very much determined by heterochrony.

But what of you and me? Is there any reason why we too shouldn't also have had our evolutionary histories molded by the all-pervasive influence of heterochrony? No reason at all. As far back as the 1920s, it was being suggested that many of our morphological features appeared to be characteristic of juvenile apes: our flat faces, reduced body hair, relatively large brains housed in thin skull bones, absence of brow ridges, and reduced jaw with too many teeth. These features would all seem to indicate that we are paedomorphs. But has that been the sum total of our evolutionary history, to be merely little more than overgrown juvenile apes? More recent studies, however, have shown that many of our morphological features are, on the contrary, peramorphic (see Minugh-Purvis and McNamara 2002 for a review).

The structure at the base of our skull that enables us to walk upright and face forward is nothing at all like any structure in juvenile apes. Our overall large body size, relatively large legs, structure of our pelvis, enlarged cranium and brain, and even our big feet are peramorphic features arising from the delay in onset of our maturity (hypermorphosis) compared with ancestral apes. In terms of our extended growth period, we are the late finishers of the ape world. Each part of our development-embryonic, infantile, and juvenile-has been relatively extended, compared with our ancestors. Such extension of succeeding growth stages during ontogeny is known as "sequential hypermorphosis" (McNamara 2002) and has been shown to be critical in the evolution of our brain (Rice 2002). This prolonged period of pre-adult development has resulted not only in our large body but especially our larger brain, which has allowed a longer period to be spent in the critical phase of learning. We are a classic example of dissociated heterochrony, where some peramorphic features are developmental trade-offs for other, paedomorphic, features: some parts of our anatomy are relatively retarded, compared with our ancestors, but others have developed beyond. Arguably, it is these peramorphic features which are the ones that have led to the success of our species on this planet, and all that that entails.

Acknowledgments I am grateful to Kat Willmore for inviting me to contribute to this volume. I also wish to thank Philipp Mitteroecker and 
an anonymous referee for their constructive comments on the manuscript.

\section{References}

Aiello LC, Wheeler P. The expensive-tissue hypothesis. Curr Anthropol. 1995;36:199-221.

Alberch P, Gould SJ, Oster GF, Wake DB. Size and shape in ontogeny and phylogeny. Paleobiology. 1979;5:296-317.

Brown L, Rockwood LL. On the dilemma of horns. Nat Hist. 1986;95 (7):54-61.

Chinsamy A. Physiological implications of the bone histology of Syntarsus rhodesiensis (Saurischia: Theropoda). Pal Af. 1990;27:77-82.

Cook D. Sexual selection in dung beetles I. A multivariate study of the morphological variation in two species of Onthophagus (Scarabaeidae: Onthophagini). Aust J Sci. 1987;35:123-32.

Darwin C. The origin of species by means of natural selection. 1st ed. London: John Murray; 1859.

Darwin C. The origin of species by means of natural selection. 6th ed. London: John Murray; 1878.

Denoël M, Ivanović A, Džukić G, Kalezić ML. Sexual size dimorphism in the evolutionary context of facultative paedomorphosis: insights from European newts. BMC Evol Biol. 2009. doi:10.1186/1471-2148-9-278.

Dommergues J-L. Ammonoids . In McNamara KJ editor. Evolutionary trends. London: Belhaven Press; 1990. p. 162-187.

Erickson GM, de Ricqlès A, de Buffrénil V, Molnar RE, Bayless MK. Vermiform bones and the evolution of gigantism in Megalania-how a reptilian fox became a lion. Jl Vert Pal. 2003;23:966-70.

Erickson GM, Makovicky PJ, Currie PJ, Norell MA, Yerby SA, Brochu CA. Gigantism and comparative life-history parameters of tyrannosaurid dinosaurs. Nature. 2004;430:772-5.

Franks SJ, Weis AE. A change in climate causes rapid evolution of multiple life-history traits and their interactions in an annual plant. J Evol Biol. 2008;21:1321-34.

Garstang W. The morphology of the Tunicata, and its bearing on the phylogeny of the Chordata. Q Jl Micr Sci. 1928;75:51-187

Gerber S. Comparing the differential filling of morphospace and allometric space through time: the morphological and developmental dynamics of Early Jurassic ammonoids. Paleobiology. 2011:37:369-82.

German RZ, Hertweck DW, Sirianni JE, Swindler DR. Heterochrony and sexual dimorphism in the Pig tailed Macaque (Macaca nemestrina) Am Jl Phys Anthrop. 1994;93:373-380.

Germonpré M, Sablin MV, Stevens RE, Hedges REM, Hofreiter M, Stiller M, et al. Fossil dogs and wolves from Palaeolithoc sites in Belgium, the Ukraine and Russia: osteometry, ancient DNA and stable isotopes. J Arch Sci. 2009;36:473-90.

Gould SJ. Ontogeny and phylogeny. Cambridge: Belknap Press of Harvard University Press; 1977.

Hafner JC, Hafner MS. Heterochrony in rodents. In: McKinney ML editor. Heterochrony in evolution: a multidisciplinary approach. New York: Plenum Press; 1988. p. 217-235.

Hall BK. Evolutionary developmental biology. London: Chapman and Hall; 1992.

Hallam A. Evolutionary size increase and longevity in Jurassic bivalves and ammonites. Nature 1975;258:493-496.

Hone WDE, Benton MJ. The evolution of large size: how does Cope's Rule work? Trends Ecol Evol. 2005;20:4-6.

Hone WDE, Benton MJ. Cope's Rule in the Pterosauria, and differing perceptions of Cope's Rule at different taxonomic levels. J Evol Biol. 2007;20:1164-70.
Jablonski D. Micro- and macroevolution: scale and hierarchy in evolutionary biology and paleobiology. Paleobiology. 2000;26 (4):15-52. In Erwin DH, Wing SL, editors. Deep Time: Paleobiology's Perspective. Supplement to Paleobiology 26 (4). Lawrence, Kans.: Paleontological Society.

Kelly CD, Adams DC. Sexual selection, ontogenetic acceleration, and hypermorphosis generates male trimorphism in Wellington Tree Weta. Evol Biol. 2010;37:200-209.

Klingenberg CP. Heterochrony and allometry: the analysis of evolutionary change in ontogeny. Biol Rev. 1998;73:79-123.

Korn D. Impact of environmental perturbations on heterochronic development in Palaeozoic ammonoids. In: McNamara KJ editor. Evolutionary change and heterochrony. Chichester: John Wiley and Sons. 1995 ; p. 245-260.

McKinney ML. editor. Heterochrony in evolution: a multidisciplinary approach. New York: Plenum; 1988

McKinney ML, McNamara KJ. Heterochrony: the evolution of ontogeny. New York: Plenum Press; 1991.

McNamara KJ. Heterochrony and phylogenetic trends. Paleobiology. 1982;8:130-42.

McNamara KJ. A guide to the nomenclature of heterochrony. J Paleontol. 1986a;57:461-73

McNamara KJ. The role of heterochrony in the evolution of Cambrian trilobites. Biol Rev. 1986b;61:121-156.

McNamara KJ. The abundance of heterochrony in the fossil record. In: McKinney ML, editor. Heterochrony in evolution: a multidisciplinary approach. New York: Plenum Press; 1988. p. 287-325.

McNamara KJ, editor. Evolutionary trends. London: Belhaven Press; 1990.

McNamara KJ, editor. Evolutionary change and heterochrony. Chichester: John Wiley and Sons; 1995a.

McNamara KJ. Sexual dimorphism: the role of heterochrony. In: McNamara KJ, editor. Evolutionary change and heterochrony. Chichester: John Wiley and Sons; 1995b. p. 65-89.

McNamara KJ. Shapes of time: the evolution of growth and development. Baltimore: Johns Hopkins University Press; 1997.

McNamara KJ, Long JA. The role of heterochrony in dinosaur evolution. In: Brett-Surman M, Holtz TR, Farlow JO, editors. The complete dinosaur. Bloomington: Indiana University Press; 2012. p. 779802.

McNamara KJ. Sequential hypermorphosis: the key to hominid evolution. In: Minugh-Purvis N, McNamara, KJ editors. Human Evolution and Developmental Change. Baltimore: Johns Hopkins University Press; 2002. p. 102-121.

McNamara KJ, McKinney ML. Heterochrony, disparity, and macroevolution. Paleobiology. 2005;31(2):17-26.

McNamara KJ, Yu F, Zhou Z. Ontogeny and heterochrony in the oryctocephalid trilobites Changaspis, Duyunaspis and Balangia from the Lower Cambrian of China. Palaeontology. 2006;48:119.

Minugh-Purvis N, McNamara KJ, editors. Human evolution through developmental change. Baltimore: Johns Hopkins University Press; 2002.

Mitteroecker P, Gunz P, Bookstein FL. Heterochrony and geometric morphometrics: a comparison of cranial growth in Pan paniscus versus Pan troglodytes. Evol Dev. 2005;7:244-58.

Morey DF. The early evolution of the domestic dog. Am Sci. 1994;82:336-47.

Padian K, de Ricqlès AJ, Horner JR. Dinosaurian growth rates and bird origins. Nature. 2001;412:405-8.

Reilly SM, Wiley EO, Meinhardt DJ. An integrative approach to heterochrony: the distinction between interspecific and intraspecific phenomena. Biol J Linn Soc. 1997;60:119-43.

Reznick D, Bryant MJ, Bashey F. R- and K-selection revisited: the role of population regulation in life-history evolution. Ecology. 2002;83:1509-20. 
Rice SH. The analysis of ontogenetic trajectories: when a change in size or shape is not heterochrony. Proc Natl Acad Sci. 1997;94:907-12.

Rice S. The role of heterochrony in primate brain evolution. In: Minugh-Purvis N, McNamara KJ editors. Human evolution and developmental change. Baltimore: Johns Hopkins University Press; 2002. p. 154-170.

Richardson MK, Brakefield PM. Hotspots for evolution. Nature. 2003;424:894-5.

Richardson MK, Oelschläger HHA. Time, pattern, and heterochrony: a study of hyperphalangy in the dolphin embryo flipper. Evol Dev. 2002;4:435-44

Rittmeyer EN, Allison A, Gründler MC, Thompson DK, Austin CC. Ecological guild evolution and the discovery of the world's smallest vertebrate. PLoS One. 2012;7:e29797.
Sander PM, Klein N. Developmental plasticity in the life history of a prosauropod dinosaur. Science. 2005;310:1800-2.

Slack F, Ruvkun G. Heterochronic genes in development and evolution. Biol Bull. 1998;195:375-6.

Tills O, Rundle SD, Salinger M, Haun T, Pfenninger M, Spicer JI. A genetic basis for intraspecific differences in developmental timing? Evol Dev. 2011;13:542-8.

Wayne RK. Cranial morphology of domestic and wild canids: the influence of development on morphological change. Evolution. 1986;40:243-61.

Webster M, Sheets HD, Hughes NC. Allometric patterning in trilobite ontogeny: testing for heterochrony in Nephrolenellus. In: Zelditch ML, editor. Beyond heterochrony. New York: Wiley; 2001. p. 10544. 